\title{
Correction to: Calibration of Laser Penetration Depth and Absorptivity in Finite Element Method Based Modeling of Powder Bed Fusion Melt Pools
}

\author{
Jaewoong Kim ${ }^{1}$ - Seulbi Lee ${ }^{1}$ Jae-Keun $\mathrm{Hong}^{2} \cdot$ Namhyun Kang $^{1} \cdot$ Yoon Suk Choi ${ }^{1}$
}

Published online: 25 February 2020

(c) The Korean Institute of Metals and Materials 2020

\section{Correction to: Metals and Materials International https://doi.org/10.1007/s12540-019-00599-3}

In the original publication of the article, Fig. 15 was published incorrectly. The y-axis title in Fig. 15 should be ' $d_{p}$ calculated using Eq. $(4)(\mu \mathrm{m})$ '. The corrected Fig. 15 is given in this correction.

The original article can be found online at https://doi.org/10.1007/ s12540-019-00599-3.

Yoon Suk Choi

choiys@pusan.ac.kr

1 School of Materials Science and Engineering, Pusan National University, Busan 46241, Republic of Korea

2 Titanium Department, Korea Institute of Materials Science, Changwon 51508, Republic of Korea 


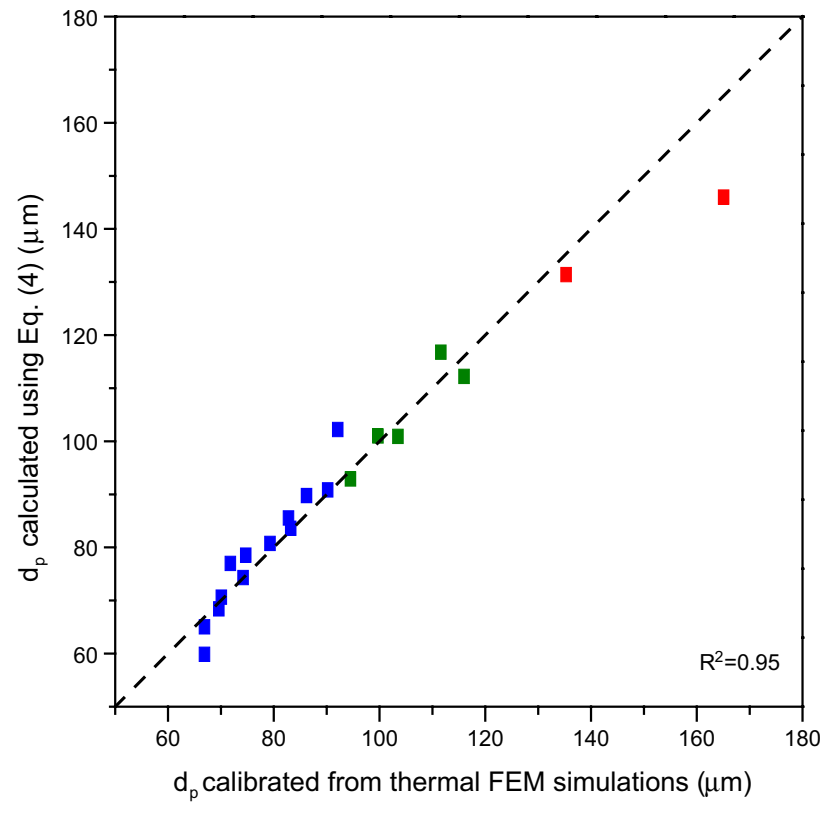

Fig. 15 Comparison of laser penetration depths calculated from Eq. (4) and calibrated from thermal FEM simulations
Publisher's Note Springer Nature remains neutral with regard to jurisdictional claims in published maps and institutional affiliations. 